\title{
PRIMARY LARGE B CELL LYMPHOMA OF THE PAROTID GLAND: CASE REPORT
}

\author{
Almothafar $\mathrm{B}^{1}$, Wong $\mathrm{L}^{2}$, Noorafidah $\mathrm{MD}^{2}$ \\ 1 School of Medicine, Universiti Malaysia Sabah, Kota Kinabalu, Sabah, Malaysia \\ 2 Queen Elizabeth Hospital, Kota Kinabalu, Sabah, Malaysia
}

\begin{abstract}
Primary parotid lymphoma is uncommon and rarely suspected. In most cases, the disease would have disseminated at the time of diagnosis. We describe a case of primary non-Hodgkin's lymphoma of the parotid gland which progressed to the central nervous system. Clinical history is of limited value in identifying this condition. Diagnostic imaging studies (CT or MRI) may indicate whether or not the mass is salivary in origin but do not help to confirm the diagnosis. In this case, it was deemed that FNA alone is incapable of determining the precise histological subtype for lymphoma, whilst a tru-cut biopsy demonstrated a more sensitive method of determining the diagnosis. The lessons learned from this case would prove useful for other health care providers to make an early diagnosis and hopefully manage more effectively if similar conditions appear in their practice. Performing the appropriate measures can help to not only improve the prognosis but may even avert the prospect of unnecessary surgery.
\end{abstract}

KEYWORDS: non-Hodgkin's lymphomas, neck, parotid gland, salivary gland

\section{Correspondence:}

Basim A.M.H.Almothafar, FRCS-Glasgow, DS, MBChB

Associate professor, Department of Surgery

School of Medicine, Universiti Malaysia Sabah

Jalan UMS, 88400 Kota Kinabalu,Sabah, Malaysia

E-mail: basim_amh@yahoo.com

\section{Introduction}

The head and neck region is the most common site where malignant lymphomas occur, however malignant lymphoma of the parotid gland is relatively rare [1]. The large majority of primary lymphomas of salivary gland involve the parotid gland, but several cases of submaxillary gland disease have been previously reported [2]. In the present article, we report a case of primary non-Hodgkin's lymphoma of the parotid gland which progressed to the central nervous system of which without invasive investigation would not have otherwise revealed the presenting diagnosis.

\section{Case report}

A 66-year-old woman presented in the surgical clinic with a swelling at the left parotid area for one-week duration which was preceded by low grade fever for a month. The patient had a past history of rheumatoid arthritis, hypertension and osteoporotic compression fractures of L2 \& L3. On examination, there was a $7 \mathrm{~cm} \mathrm{x}$ $5 \mathrm{~cm}$ tender left parotid bluish swelling, firm and fixed to skin and underlying structures. The facial nerve was intact with no palpable cervical lymph nodes. The abdomen was not distended with no organomegaly. However, there was tenderness over the right side of the lumber and sacral spines.

Fine needle aspiration cytology (FNAC) was performed. The finding was suggestive of lymphoproliferative lesion (Figure 1), but was inconclusive. A multi-sliced contrastenhanced CT scan of the neck (Figure 2) followed by axial and coronal reconstruction was performed. It demonstrated a left parotid mass with enlarged left cervical nodes, signs suggestive of lymphoma. A core biopsy (Figures 3,4) of the left parotid gland was thus performed. The finding was 
compatible with the diagnosis of diffused large B cell lymphoma (DLBCL).

The above investigations took up to 6 weeks, during which the patient started to feel numbness over the lower limbs, difficulty in walking, urinary incontinence and dyspnoea. On examination of the patient, the parotid mass increased in its size to reach $20 \mathrm{~cm} \times 20 \mathrm{~cm}$, with palpable right inguinal lymph nodes, hypotonia in both lower limbs and absence of sensation below the nipple line.

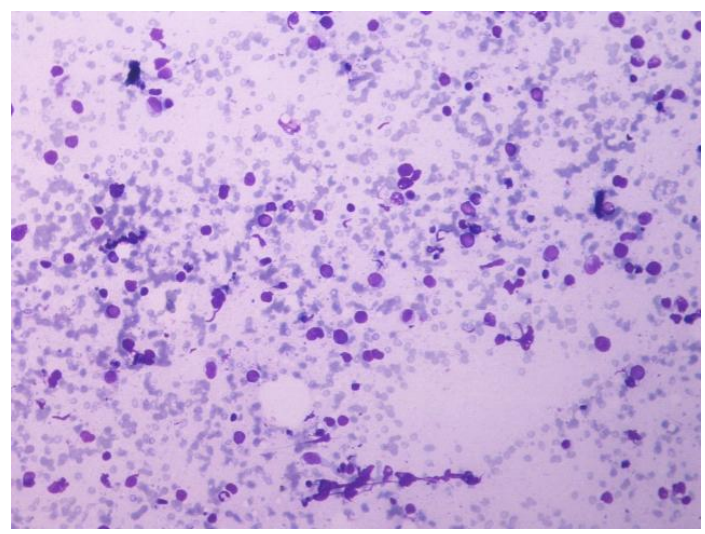

Figure 1. Fine needle aspiration cytology of parotid lesion

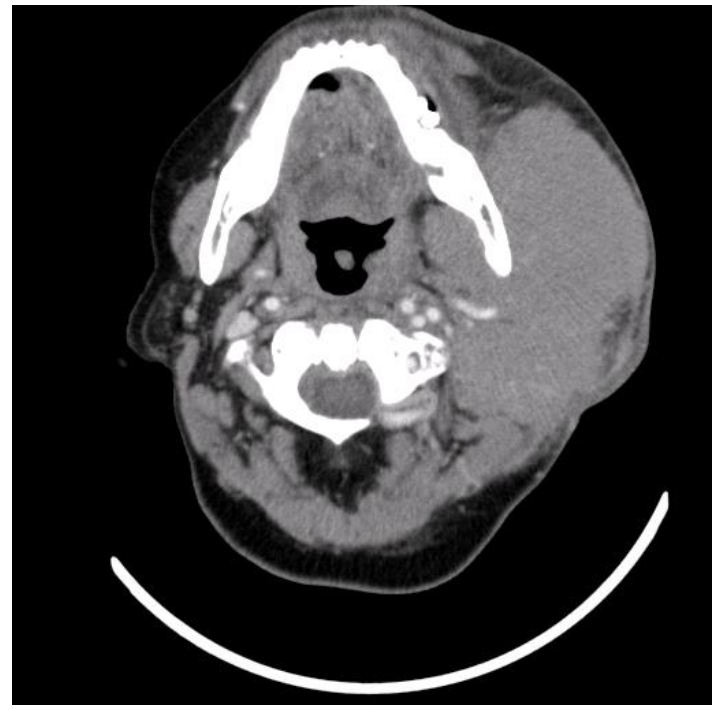

Figure 2. Transverse section of CT head showing a large left parotid tumour

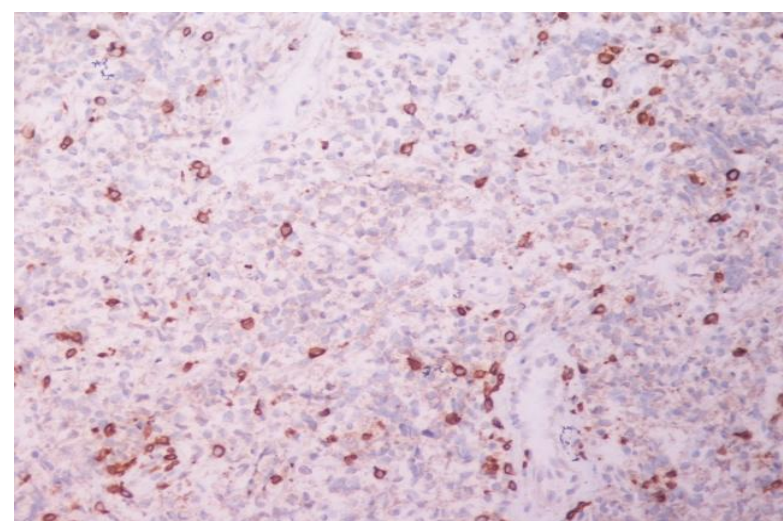

Figure 3. Core biopsy of parotid mass showing diffuse lymphoid infiltrate and the tumour cells were negative for $C D 3$

Chest X-ray showed signs of left pleural effusion. Then MRI of the thoracolumbar area (Figure 5) was obtained. The findings were consistent with tumour infiltration involving the intramedullary, intradural, intramuscular and vertebral bodies of T2 to T8 vertebrae. The patient was diagnosed as stage IVE diffuse large B cell primary lymphoma of parotid gland involving the spine. In view of her frail condition, a tailored regimen consisted of high dose methotrexate for optimal CNS penetration and a lower dose of alkylating agent and anthracycline was used. Urgent radiotherapy with intention to salvage her spinal cord compression, 50 Gy in 5 fractions in five days, was given to T1-T9, followed by the first cycle of chemotherapy (Methotrexate, Vincristine, Cyclophosphamide, and Adriamycin) and Dexamethasone. Then, another cycle (Methotrexate, Vincristine, Ifosphamide, Ara C) and Dexamethasone were given 3 weeks later.

After the second cycle of chemotherapy, the patient suffered attacks of neutropenia sepsis and pneumonia, and needed potent antibiotics. Even though the tumour mass subsided with the use of chemotherapy, the neurological deficit, specifically paraparesis, did not improve; she was completely bed-bound. In view of the poor quality of life, the family opted for palliative care after the second chemotherapy. The patient died from 
disseminated disease and septicemia one month later. The patient's family refused an autopsy request.

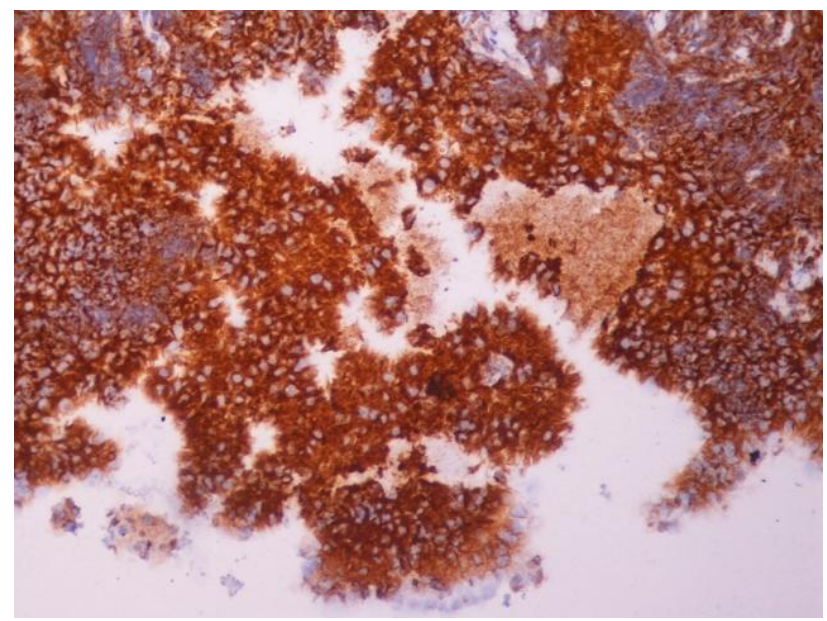

Figure 4. Core biopsy of parotid mass showing diffuse lymphoid infiltrate and the tumour cells were positive for $C D 20$

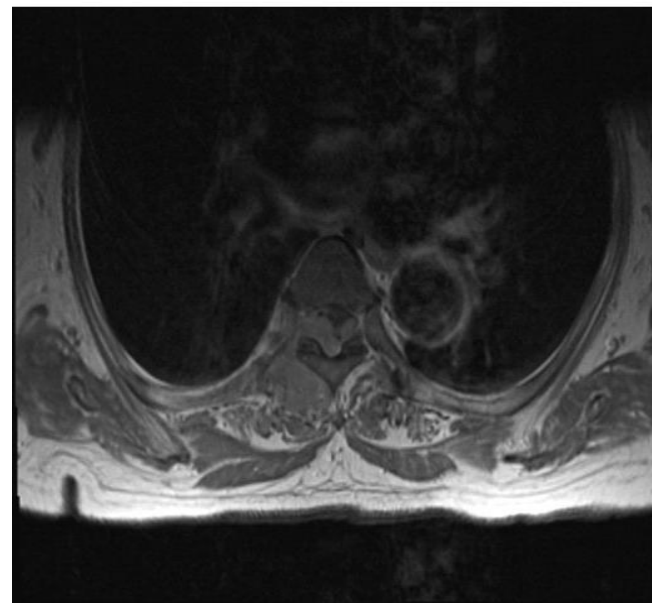

Figure 5. Magnetic resonance imaging of the thoracolumbar area

\section{Discussion}

Malignant lymphomas developing primarily in the salivary glands are uncommon and reported as a case reports in many literatures [3-9]. At the time of diagnosis, most salivary gland lymphomas particularly those of lower grades are generally disseminated [2]. Clinical history is of limited value in identifying such patients and, because of this difficulty in clinical diagnosis, Leon Barnes \& colleagues suggest the following clinical features which might help in reaching the diagnosis: development of a parotid mass in a patient with a known history of malignant lymphoma; in a patient with an immune disorder, rheumatoid arthritis (like in the case of the present report), or acquired immunodeficiency syndrome; in a patient with a previous diagnosis of "benign lymphoepithelial lesion"; multiple masses in a unilateral parotid gland or bilateral parotid masses; or parotid mass associated with multiple, enlarged unilateral or bilateral cervical lymph nodes [10].

FNA alone is often incapable of determining the precise histological subtype for lymphoma. If lymphoma is suspected, FNA is typically followed by an open biopsy [11]. Diagnostic imaging studies (CT or MRI) indicate whether or not the mass is salivary in origin but do not help classify it histologically [11].

In our case, there was a delay in the diagnosis because:

1. The lymphoma was not one of the differential diagnoses.

2. The FNAC that was done for her was inconclusive.

3. The CT and MRI were used for staging of a tumor. It might suggest the diagnosis of lymphoma but could not establish a histological diagnosis which was essential prior to starting lymphoma therapy.

4. Tru cut biopsy was diagnostic but done as the last investigation.

The treatment of lymphoma is based on histological subtype and the disease stage at diagnosis rather than on the type of tissue originally involved. This means that diagnostic tissue does not necessarily have to be taken from the parotid if there is disease elsewhere. The problem therefore is how to identify those parotid masses that might be lymphoma so that parotidectomy can be avoided.

The most common subtype of aggressive $\mathrm{NHL}$ is diffuse large B-cell lymphoma (DLBCL) [12]. The R- 
CHOP (rituximab, cyclophosphamide, doxorubicin $\mathrm{HCl}$, vincristine and prednisone) regimen has been approved as gold standard chemotherapy to treat aggressive B$\mathrm{NHL}$. However, in this case, in view of the CNS involvement, a chemotherapy regimen containing high dose methotrexate was used.

CNS involvement has a significant impact on survival rates. Hollender \& colleagues who studied up to 170 cases with systemic central nervous system involvement of non-Hodgkin's lymphoma reports a very poor prognosis following secondary central nervous system lymphoma, with an overall median survival of 2.6 months, and with only $12 / 140$ patients (8.6\%) being in a complete remission at the last follow-up [13]. While Seiichi Yoshida $\&$ colleagues found the overall median survival of the 58 CNS lymphoma patients was only 13.4 months (ranging from 1 to 32 months) [14].

\section{Conclusions}

1. Primary parotid lymphoma is uncommon and rarely suspected, and mostly already disseminated at the time of diagnosis, but early diagnosis can improve the prognosis and avoid the surgery so it should be listed in the differential diagnosis of a parotid mass.

2. Some clinical features might help in raising the suspicion of the diagnosis, e.g. a past medical history of rheumatoid arthritis, as in this case.

3. Tru cut biopsy is more sensitive than FNAC in reaching the diagnosis; we suggest Tru cut to be the first choice in diagnostic pathology investigation.

\section{References}

1. Nagata $M$, Kumazawa $H$, Iwai $H$, Momotani $A$, Shiraishi S, Yamashita T. Study of malignant lymphoma in the parotid gland region. Nippon Jibiinkouka Gakkai Kaiho 1996; 99: 918-25 (in Japanese).

2. Rosai J. Rosai and Ackerman's Surgical patology. $9^{\text {th }}$ ed. India , Elsevier Inc, 2004: 890-97
3. Urano M, Mizoguchi $\mathrm{Y}$, Nishio $\mathrm{T}$, Abe M, Kuroda M, Saito S, Sakurai K. Composite lymphoma arising in the parotid gland: A case report. Auris Nasus Larynx 2004; 31(1): 89-93.

4. Shvidel L, Sigler E, Shtalrid M, Feldberg E, Berrebi A. Parotid gland involvement, the presenting sign of high grade non-Hodgkin lymphoma in two patients with Gaucher disease and sicca syndrome. J Inherit Metab Dis 2007; 30 (5): 825.

5. Gouveris H, Hansen $T$ und K. Franke.Solitary extramedullary plasmacytoma and granulomatous sialadenitis of the parotid gland preceding a B-cell non-Hodgkin's lymphoma. Mund-, Kiefer- und Gesichtschirurgie Springer Berlin / Heidelberg. 2006; 10(2): 123-6.

6. Hirokawa N, Hareyama M, Akiba H, et al . Diagnosis and Treatment of Malignant Lymphoma of the Parotid Gland. Jap J Clin Oncol; 28(4): 245-49

7. Masuda M, Segawa Y, Joe AK, Hirakawa N, Komune S. A case of primary Hodgkin's lymphoma of the parotid gland. Auris Nasus Larynx September 2008; 35 (3): 440-2

8. Fujimura $K$, Yoshida $M$, Sugimoto $T$, Kuroda $Y$, Fujiyoshi T. Two cases of non-Hodgkin's lymphoma in the accessory parotid gland. Auris Nasus Larynx $\mathrm{J}$ 2004; 31(2): 195-8.

9. Urano M, Mizoguchi $\mathrm{Y}$, Nishio $\mathrm{T}$ et al. Composite lymphoma arising in the parotid gland: a case report. Auris Nasus Larynx Mar 2004; 31(1): 89-93.

10. Barnes L, Myers, EN, Prokopakis, EP. Primary Malignant Lymphoma of the Parotid Gland. Arch Otolaryngol Head Neck Surg May 1998; 124(5):5737.

11. Wiley W. Souba, Mitchell P. Fink, Gregory J. Jurkovich, Larry P. Kaiser, William H. Pearce, John H. Pemberton, and Nathaniel J. Soper. ACS Surgery principles and practice. American college of surgeons, WebMD Professional Publishing :Danbury, Connecticut 2005; 154-6. 
12. Jaffe ES, Harris NL, Stein $\mathrm{H}$, et al. (Ed.). World Health Organization Classification of Tumors. Pathology and Genetics of Tumors of Haematopoietic and Lymphoid Tissues. Lyon, IARC Press, 2001; 171-174.

13. Hollender A, Kvaloy S, Lote K, Nome O, Holte H. Prognostic factors in 140 adult patients with nonHodgkin's lymphoma with systemic central nervous system (CNS) involvement .A single centre analysis. Eur J Cancer 2000; 36: 1762-8.

14. Yoshida S, Morii K, Watanabe M, Saito $T$. Characteristic Features of Malignant Lymphoma With Central Nervous System Involvement. Surg Neurol 200; 53(2):163-7. 